\title{
Downstream changes in firing regularity following damage to the early auditory system
}

\author{
Dan FM Goodman ${ }^{1 *}$, Alain de Cheveigné2 ${ }^{2}$ Ian M Winter ${ }^{3}$ Christian Lorenzi $^{2}$ \\ From 24th Annual Computational Neuroscience Meeting: CNS*2015 \\ Prague, Czech Republic. 18-23 July 2015
}

We demonstrate how an abstract mathematical model that approximates a wide range of more detailed models can be used to make predictions about hearing lossrelated changes in neural behaviour.

One consequence of neurosensory hearing loss (noiseinduced and aging-related) is a reduced ability to understand speech, particularly in noisy environments, and sometimes beyond what would be predicted from reduced audibility. Indeed, this type of speech deficit can occur in listeners with near-normal hearing thresholds [1]. A promising avenue of investigation to explain this comes from experimental results in mice showing that there can be a permanent loss of auditory nerve fibres (ANFs) following "temporary" noise-induced hearing loss (i.e. when thresholds return to normal after a few weeks) [2]. The downstream consequences of this loss of fibres has not yet been systematically investigated (although see [3]). We predict, using a theoretical analysis that applies to a wide range of neural models, that the regularity of the spike trains of many neurons in the cochlear nucleus (the next structure after the auditory nerve) will decrease following a reduction in the number of input cells.

We present a mathematical analysis of the stationary behaviour of "chopper" cells in the ventral cochlear nucleus, approximating them by a stochastic process that is entirely characterised by its mean, standard deviation and time constants. Furthermore, these constants can be straightforwardly related to physiologically significant parameters including the number of inputs and their average firing rates. From this approximation, we can compute the regularity of the chopper cell spike trains measured as the coefficient of variation of their interspike intervals $(\mathrm{CV})$.

\footnotetext{
* Correspondence: d.goodman@imperial.ac.uk

${ }^{1}$ Department of Electrical and Electronic Engineering, Imperial College

London, London, UK

Full list of author information is available at the end of the article
}

One simple prediction of this model is that when the intensity of a stimulus changes, leading to a change in the average firing rate of the ANF inputs, there will be a corresponding change in the regularity of the chopper cell spike train. This prediction poses problems for the widely used scheme for classifying chopper cells as sustained or transient based on their ongoing CVs as it implies that the classification could be level-dependent. We present a re-analysis of an existing experimental data set that demonstrates that ongoing $\mathrm{CV}$ is indeed leveldependent in the majority of chopper cells, and that in some cells $(>7 \%)$ this leads to a level-dependence in their classification.

Assuming a homeostatic regulation of long term firing rates, a loss of ANFs will lead to an increase in the standard deviation of the stochastic process and a consequent increase in the CV of the chopper cell. Some choppers that were previously classified as sustained will become transient, a substantial change in their behaviour that is highly likely to disrupt auditory processing. While the function of chopper cells is still debated, one suggested role is in the coding of temporal envelope [4], which is widely agreed to be essential for understanding speech. Loss of ANFs could therefore lead to a disruption of the processing of temporal envelope, and consequently degrade speech intelligibility. We briefly conclude by discussing the challenges of testing this hypothesis experimentally.

\begin{abstract}
Authors' details
${ }^{1}$ Department of Electrical and Electronic Engineering, Imperial College London, London, UK. ${ }^{2}$ Laboratoire des Systèmes Perceptifs, Centre National de la Recherche Scientifique and École Normale Supérieure, Paris, France. ${ }^{3}$ Centre for the Neural Basis of Hearing, The Physiological Laboratory, Department of Physiology, Development and Neuroscience, University of Cambridge, Cambridge, UK.
\end{abstract}

Published: 18 December 2015 


\section{References}

1. Leger AC, Moore BCJ, Lorenzi C: Temporal and spectral masking release in low-and mid-frequency regions for normal-hearing and hearingimpaired listeners. J Acoust Soc Am 2012, 131(2):1502-1514.

2. Kujawa SG, Liberman MC: Adding insult to injury: cochlear nerve degeneration after "temporary" noise-induced hearing loss. J Neurosci 2009, 29(45):14077-14085.

3. Lopez-Poveda EA, Barrios P: Perception of stochastically undersampled sound waveforms: a model of auditory deafferentation. Front Neurosci 2013, 7:124.

4. Lorenzi C, Micheyl C, Berthommier F: Neuronal correlates of perceptual amplitude-modulation detection. Hearing Research 1995, 90(1-2); 219-227.

doi:10.1186/1471-2202-16-S1-011

Cite this article as: Goodman et al:: Downstream changes in firing regularity following damage to the early auditory system. $B M C$ Neuroscience 2015 16(Suppl 1):O11.

\section{Submit your next manuscript to BioMed Central} and take full advantage of:

- Convenient online submission

- Thorough peer review

- No space constraints or color figure charges

- Immediate publication on acceptance

- Inclusion in PubMed, CAS, Scopus and Google Scholar

- Research which is freely available for redistribution

Submit your manuscript at www.biomedcentral.com/submit 